\title{
PREDICTORS OF LEGIONELLA OCCURRENCE IN DENTAL UNIT WATERLINES OF A HIGHLY COLONIZED DENTAL HOSPITAL
}

\author{
Giuseppe A. M essano ${ }^{1}$, M ohd M asood ${ }^{2}$, Patrizio Palermo ${ }^{3}$, Stefano Petti ${ }^{1}$ \\ 1 SAPIENZA UNIVERSITY, DEPARTMENT OF PUBLIC HEALTH AND INFECTIOUS DISEASES, ROME, ITALY; \\ 2 CENTRE OF STUDIES FOR COMMUNITY DENTISTRY, FACULTY OF DENTISTRY, \\ UNIVERSITI TEKNOLOGI MARA, SHAH ALAM, MALAYSIA; \\ 3 SAPIENZA UNIVERSITY, DEPARTMENT OF CARDIOVASCULAR, RESPIRATORY, NEPHROLOGIC AND GERIATRIC SCIENCES \\ AND S. CAMILLO-FORLANINI HOSPITAL, ROME, ITALY
}

\begin{abstract}
Introduction. Legionella is frequently detected in Dental Unit Waterlines (DUWLs). Although such a high occurrence is not necessarily associated with high risk for Legionnaire's disease among patients and staff, it is prudent to monitor DUWLs for Legionella periodically. Since this procedure is long and expensive, surrogate markers are frequently used.

Aim. To investigate whether surrogate markers are predictive of Legionella detection in DUWLs in a highly colonized dental hospital.

Material and methods. DUWLs from a dental hospital where legionellae were detected intermittently throughout a period of ten years was considered. The investigated predictors were total viable flora (TVF) at $37^{\circ} \mathrm{C}$ and at $22^{\circ} \mathrm{C}$, Pseudomonas (legionellae competitor) occurrence and season. Multivariate analysis was made and, using the best fitting logistic regression model, the probability to detect legionellae in water from DUWLs was estimated.

Results. Legionellae were detected in 52\% water samples collected in summertime and never detected in wintertime at levels ranging between 0 and 200 colony forming units $(C F U) / L$. The odds ratio of legionellae occurrence were 25.0 for Pseudomonas undetected vs. detected, 108.3 for summertime vs. wintertime, 2.2-2.3 for TVF levels at $37^{\circ} \mathrm{C}$ and $22^{\circ} \mathrm{C}$ $>200 \mathrm{CFU} / \mathrm{mL}$ vs. $\leq 200 \mathrm{CFU} / \mathrm{mL}$. A 29\% probability to detect legionellae from DUWLs, where Pseudomonas was undetected, TVF levels were $>200 \mathrm{CFU} / \mathrm{mL}$ and in summertime, was estimated.

Conclusion. Despite legionellae were ubiquitous in the dental hospital during the study period, in the most favourable conditions for Legionella growth (lack of competitor, high biofilm and hot weather), legionellae were detected in almost one third of DUWLs.
\end{abstract}

Key words: dental unit waterline, Legionella, Pseudomonas, water quality

\section{Introduction}

Aquatic biofilm is a potential source of nosocomial and community-acquired infections, due to the occurrence of opportunistic pathogens. More specifically, Pseudomonas aeruginosa, well known in the hospital environment, is the cause of $10-20 \%$ of hospital acquired infections (HAI), its extreme resistance to antibiotics is responsible for high mortality rate. Legionella pneumophila causes $4-20 \%$ of cases of community-acquired pneumonia and has been ranked as the second-third most frequent cause of pneumonia requiring hospitalization ${ }^{1,2}$. A peculiar characteristic of aquatic biofilms is that bacteria, organized in sessile phase, produce extracellular polysaccharides that help increase the resistance to antimicrobial agents ${ }^{3}$. In addition, bacteria organized in biofilms may survive for long periods. Indeed, P. aeruginosa can survive up to five months without nutrients and $10^{\circ} \mathrm{C}$ and L. pneumopila more than fifteen days without protozoa, essential for replication ${ }^{4}$.

Legionellaceae are distributed worldwide in low numbers in all types of aquatic habitats. Legionellae may enter the dental unit waterlines (DUWLs) from the mains drinking water or from the air conditioning system. Legionella multiplication into DUWL requires the presence of aquatic biofilm, which, in turn, is promoted by water stagnation, a condition typical of most dental units, which are frequently not

(c) 2013 Faculty of Medicine in Niš. Clinic of Dentistry in Niš. All rights reserved / (C) 2013 Medicinski fakultet Niš. Klinika za stomatologiju Niš. Sva prava zadržana

\author{
Address for correspondence: \\ Dr. Giuseppe AlessioMessano \\ Department of Public Health and Infectious Diseases \\ Sapienza University \\ P.le Aldo Moro 5, 00185 Rome, Italy \\ Phone/Fax: +3906 49914667 \\ Email: giuseppe.messano@yahoo.it
}


used for more than $12 \mathrm{~h}$ daily, during workdays, and $60 \mathrm{~h}$ during weekends ${ }^{5}$. Legionellae also require amoebae and other protozoa, few nutrients and temperature ranging between $20^{\circ} \mathrm{C}$ and $45^{\circ} \mathrm{C}$. Incidentally, intracellular growth protects these microorganisms from the bactericidal action of biocides, chlorination or relatively elevated temperatures. The aforementioned conditions are frequently found in dental healthcare settings and Legionella levels in water samples from DUWLs as high as 102-105 colony forming units (CFU)/mL are reported $^{6}$. Once established, legionellae can become resident members of the aquatic biofilm for years ${ }^{4,7}$. All these characteristics imply that frequency of Legionella detection in DUWLs is necessarily high. For example, an Italian national survey reported a detection rate as high as $33.3 \%^{8}$, similar values are reported from US and UK (reviewed by Pankhurst and Coulter ${ }^{6}$ ). However, these data come from hospital-based studies where the environmental conditions are not the same as those found in the office of the general dental practitioner (GDP) and inferring that L egionella is frequent in all dental healthcare settings is, therefore, misleading. Indeed, low detection rates are reported in surveys from GDPs' offices in UK $(0.4 \%)^{9}$ and EU $(4 \%)^{10}$.

Although legionellae are more or less frequently detected in DUWLs, a different issue is to assess the risk for infection associated with DUWLs contaminated by legionellae ${ }^{11}$. Indeed, there is no conclusive evidence that a patient has ever contracted legionnaire's disease inhaling L. pneumophila serogroup ${ }^{1}$ coming from DUWLs. One fatal case is reported of an 82-year-old woman, with no apparent risk factor for L egionnaire's disease, who died after having contracted L. pneumophila-associated pneumonia. During the incubation period (2-10 days before pneumonia development), the patient attended to two appointments at a dental practice. The investigation of L. pneumophila sources found no traces in the patient's home, while this microorganism was detected in DUWLs and cold water tap of the dental office at 103-104 CFU/L level ${ }^{12}$. This event raised the level of awareness and fear among dental healthcare workers and public health experts. However, the reported case does not provide conclusive evidence that Legionnaire's disease can be transmitted during dental treatment. Firstly, the reported data do not allow to assess whether L. pneumophila contamination of the dental healthcare setting preceded patient's infection - and, therefore, was the source for the infection- or was consequent to the patient's infection. In addition, the air conditioning system was not tested for L. pneumophila occurrence, while tap water resulted contaminated, thus, in the event that environmental contamination preceded patient's infection, it is not possible to assess whether the source of infection was the air conditioning system, the tap water or the DUWL. Finally, the level of L. pneumophila in water necessary for the development of Legionnaire's disease is estimated to be at 106-108 CFU/L for showering events of 15 min with hot water ${ }^{13}$. Such an infective dose is almost one thousand times higher than the level previously reported in DUWLs. There is another fatal case of legionellosis developed by a dentist who died from pneumonia. Legionella dumoffii was detected in domestic water and in water from the dental office. It was, therefore, not possible to assess the source of infection ${ }^{14}$. There is no final evidence that prevalence of anti-Legionella antibodies, a sign of past infection, is higher among dental healthcare workers than in the general population or in non-dental controls ${ }^{9,15}$. These data suggest that, in absence of further evidence, exposure to legionellae is frequent in dental healthcare settings, but the risk for infection and L egionnaire's disease is minimal.

These data do not mean that precautions are not necessary to control for Legionella in DUWL, particularly in public health settings where these and other environment-resistant microorganisms are likely to develop and special care patients are frequently treated ${ }^{16}$. Indeed, it was previously suggested that DUWL monitoring must follow two directions. One finalized at investigating oral fluid retraction and the consequent risk for blood- and air-borne infections, another at investigating the risk for biofilm-associated opportunistic pathogens ${ }^{17}$. However, routine Legionella and Pseudomonas monitoring in dental healthcare settings is not simple and cheap. This problem led to investigate for effective predictors or risk markers $18-20$

\section{Aim}

The aim of this study was to investigate the factors associated with Legionella occurrence in DUWLs in a dental hospital where these 
microorganisms were detected for a 2-year period $^{4}$.

\section{Material and M ethods}

The water distribution system of a dental hospital in Rome was tested four times. NameIy, wintertime 2002, summertime 2002, wintertime 2003, summertime 2003. At that time, DUWLs were connected to municipal water and hot water came from tanks located at the last floor of the building. The hot water tanks were the ideal environment where Legionella species probably survived for more than ten years, as it is suggested by the fact that these microorganisms were detected during two different surveys made at 10-year interval. The hot tap water was, in turn, the source of contamination of dental offices. In 1992 the water system was disinfected through hyper-chlorination and legionellae were not detected for a long period. However, these microorganisms were detected again in 2002. It is important to highlight that no case of legionellosis among patients, dental and administrative staff was reported during this period ${ }^{4,15}$. The water system of the dental hospital was then revised, tanks were removed, most dental chairs were changed and water in DUWLs was periodically disinfected. After that, Legionella and Pseudomonas were no more detected in DUWLs and in tap water.

During the 2002-2003 survey, the level of residual chlorine, $\mathrm{pH}$ and total hardness ranged between 0.02-0.06 mg/L, 7.45-7.81 and 1.0-1.5 $\mathrm{mmol} / \mathrm{L}$, respectively. No water disinfection procedure was made during this period.

At every sampling occasion, 25 water samples $(1.2 \mathrm{~L})$ from DUWLs (air-water syringe, turbine and oral rinsing) from different dental chairs were aseptically collected into sterile bottles avoiding that the tube touched the margins of the bottle. The residual disinfectant activity of chlorine was neutralized by sodium thiosulphate at a final concentration of $0.01 \%(\mathrm{w} / \mathrm{v})$. The bottles were stored at $4^{\circ} \mathrm{C}$, transported to the laboratory and processed within two hours.

One litre of every sample was used to test for Legionella occurrence and was filtered (polyamide filters, pore size $0.2 \mu \mathrm{m}$ ), re-suspended in $10 \mathrm{~mL}$ of the original sample, vortexed for $30 \mathrm{~s}$, treated at $50^{\circ} \mathrm{C}$ for $30 \mathrm{~min}$, diluted, plated in duplicate on Charcoal-Yeast Extract Agar (CYE;
Oxoid, Ltd., Basingstoke, UK) supplemented with Legionella BCYE- $\alpha$ Growth Supplement (Oxoid) and incubated ten days at $37^{\circ} \mathrm{C}$ with $2.5 \% \mathrm{CO} 2$. Colonies with typical Legionella morphology were sub-cultured in CYE and BCYE and only those not grown on CYE were serologically identified, by means of agglutination tests and counted.

Pseudomonas occurrence was tested using $100 \mathrm{~mL}$ of each sample which were filtered (nitrocellulose filters, pore size $0.45 \mu \mathrm{m}$ ), resuspended in $10 \mathrm{~mL}$, vortexed for $30 \mathrm{~s}$, diluted, plated on to Pseudomonas Agar Base with C-F$\mathrm{C}$ supplement (Oxoid) and incubated three days at $30^{\circ} \mathrm{C}$. The colonies were counted, sub-cultured on Tryptone Soy Agar and biochemically identified by API 20 NE (API System S.A., La Balme Les Grottes, Montalieu Vercieu, France).

Total cultivable flora at $37^{\circ} \mathrm{C}$ and $22^{\circ} \mathrm{C}$ was assessed plating aliquots of sampled water on Plate Count Agar (Oxoid).

The lowest limits of detection were 10 CFU/L (Legionella), 100 CFU/L (Pseudomonas), $1 \mathrm{CFU} / \mathrm{mL}$ (cultivable flora).

The explanatory variables used to investigate the factors associated with Legionella in the output water of DUWLs were, Pseudomonas, total viable flora at $37^{\circ} \mathrm{C}$, total viable flora at $22^{\circ} \mathrm{C}$ and season. A bivariate analysis was initially made, explanatory variables were dichotomized into Pseudomonas occurrence (no vs. yes) and season (summertime vs. wintertime). As for total viable flora, we chose the threshold value suggested by the A merican Dental Association with the Statement on Dental Unit Waterlines (available at, http:// www.ada.org/1856.aspx): "water delivered to patients during nonsurgical dental procedures consistently contained no more than $200 \mathrm{CFU} /$ $\mathrm{mL}$ of aerobic mesophilic heterotrophic bacteria at any point in time in the unfiltered output of the dental unit". Given the skewed distribution of L egionella values, the outcome variable also was dichotomized into Legionella occurrence (no vs. yes). Unadjusted odds ratios (ORs) were assessed and statistically analysed through $\chi^{2}$ test with Yates correction for continuity. Multiple logistic regression analysis was used to assess the ORs adjusted for covariates for Legionella occurrence. On the basis of previously published data ${ }^{4}$ it was likely that summertime was the stronger predictor of Legionella occurrence. Therefore, data were split into winter- 
time and summertime and two separate models for each season were made. The goodness of fit of regression models was statistically analysed through likelihood ratio $\chi 2$ test and pseudo-R2. For statistical tests a significance level of $95 \%$ was chosen.

\section{Results}

Legionella was detected in $26 \%$ sampling occasions, specifically, $12 / 25(48 \%)$ times in summer 2002 and 14/25 (56\%) times in summer 2003, it was never detected in wintertime. Psuedomonas was detected in $24 \%$ sampling occasions, while total viable flora level was higher than the ADA threshold in 33\% samples at $37^{\circ} \mathrm{C}$ and $29 \%$ samples at $22^{\circ} \mathrm{C}$. Legionella species serologically identified were L. pneumophila serogroup ${ }^{6}$ and L. micdadei, while P. aeruginosa was the only Pseudomonas species biochemically identified. Legionella levels ranged between 0 and $200 \mathrm{CFU} / \mathrm{L}$, Pseudomonas between 0 and $1,040 \mathrm{CFU} / \mathrm{mL}$, total viable flora at $37^{\circ} \mathrm{C}$ between 0 and $1,356 \mathrm{CFU} / \mathrm{mL}$ and total viable flora at $22^{\circ} \mathrm{C}$ between 0 and 988 $\mathrm{CFU} / \mathrm{mL}$ (data not in Table).

Table 1 displays the bivariate associations between the investigated factors and L egionella occurrence. Total viable floras at $37^{\circ} \mathrm{C}$ and $22^{\circ} \mathrm{C}$ were not significantly associated with legionellae, while absence of Pseudomonas and summertime were strongly associated with this condition, with unadjusted ORs of 25 and 108, respectively. The logistic regression analysis provided a highly predictive model (pseudo$\mathrm{R} 2=0.45$ ), but all explanatory variables were not significantly associated with detection of legionellae (Table 2). The estimated coefficients were used to assess the probability to detect Legionella in the most favourable conditions, that is, in summertime, with Pseudomonas undetected and levels of total viable flora at $37^{\circ} \mathrm{C}$ and $22^{\circ} \mathrm{C}$ greater than the ADA limit of 200 $\mathrm{CFU} / \mathrm{mL}$. In these conditions, the probability was $29.3 \%$ (data not in Table).

Table 1. Unadjusted ORs for Legionella occurrence (95\% confidence intervals between parentheses) in DUWLs from a highly contaminated dental hospital.

\begin{tabular}{lllll}
\hline Variable & Reference value & OR & $95 \%$ confidence interval OR & $\chi 2$ test $(\mathrm{p})$ \\
\hline Psudomonas & Detected & 25.0 & $1.5-444.5$ & $9.39(\mathrm{p}=0.002)$ \\
Total viable flora at $37^{\circ} \mathrm{C}$ & $<200 \mathrm{CFU} / \mathrm{mL}$ & 2.2 & $0.9-5.4$ & $2.00(\mathrm{p}=0.15)$ \\
Total viable flora at $22^{\circ} \mathrm{C}$ & $<200 \mathrm{CFU} / \mathrm{mL}$ & 2.3 & $0.8-5.5$ & $2.21(\mathrm{p}=0.13)$ \\
Season & Wintertime & 108.3 & $6.3-1854.4$ & $32.48(\mathrm{p}<0.0001)$ \\
\hline
\end{tabular}

Table 2. Logistic regression analysis of the association between the investigated variables and probability of Legionella occurrence in DUWLs from a highly contaminated dental hospital.

\begin{tabular}{lllll}
\hline Variable & Reference value & OR & $95 \%$ confidence interval OR & t-test $(\mathrm{p})$ \\
\hline Psudomonas & Detected & $4.9 \times 10^{5}$ & $0.0-\infty$ & $0.02(\mathrm{p}=0.98)$ \\
Total viable flora at $37^{\circ} \mathrm{C}$ & $<200 \mathrm{CFU} / \mathrm{mL}$ & 2.9 & $0.6-14.6$ & $1.29(\mathrm{p}=0.19)$ \\
Total viable flora at $22^{\circ} \mathrm{C}$ & $<200 \mathrm{CFU} / \mathrm{mL}$ & 1.0 & $0.2-5.0$ & $0.01(\mathrm{p}=0.98)$ \\
Season & Wintertime & $7.0 \times 10^{6}$ & $0.0-\infty$ & $0.04(\mathrm{p}=0.97)$ \\
\hline
\end{tabular}

Log likelihood $\chi 24 \mathrm{df}=51.33 ; \mathrm{p}<0.0001 ;$ pseudo-R2 $=0.45$

\section{Discussion}

The present study is one of the papers presented at the workshop "Advances in Infection Epidemiology and Control in Dental Healthcare Settings", Department of Public Health and Infectious Diseases, Sapienza University, Rome, Italy on February 9th, 2013 21-27.

This is the first study which sought to investigate the probability to detect legionellae in the output water of DUWLs in a building which was highly contaminated by these microorganisms. Indeed, the hot water tanks contained $>200 \mathrm{CFU} / \mathrm{L}$ legionellae and hot tap water was contaminated almost everywhere in summertime. Very interesting, legionellae were never detected in wintertime, even in the hot water tanks ${ }^{4}$. One would expect that these favourable conditions for Legionella development would result in ubiquitous detection in DUWLs which were not routinely disinfected. 
Nevertheless, only $48 \%$ (in 2002) and 56\% (in 2003) of the dental units resulted contaminated in summertime, when legionellae developed and flourished throughout the hospital. In addition, the detected levels ranged between 4 and $200 \mathrm{CFU} / \mathrm{L}$ with a mean level of 31.2 CFU/L (data not in Table), a value lower than the estimated infectious dose for showering events, which could be assimilated to dental treatments for L egionella-containing aerosol production and inhalation ${ }^{13}$. Indeed, during the period of the study no case of infection was reported among staff and patients, while in 1992 anti-L egionella antibodies, suggestive of past infection, were not detected among the dental healthcare workers, but were detected in $4 \%$ of the administrative $\operatorname{staff}^{15}$. Although legionellae were never detected in DUWLs contaminated by Pseudomonas and were never detected in wintertime, these variables were not significantly predictive of Legionella occurrence in DUWLs. The addition of the two other microbiological indices, that is, total viable floras at $37^{\circ} \mathrm{C}$ and $22^{\circ} \mathrm{C}>200 \mathrm{CFU} / \mathrm{mL}$ did not increase the predictive power of the model and it was only possible to infer that in output water of DUWLs without Pseudomonas, with high levels of aerobic heterotrophic bacteria and in summertime, that is, the most favourable Legionella development promoting conditions, the probability to detect these microorganisms was of $29 \%$.

In previous studies, Zanetti and colleagues found that in DUWLs with L. pneumophila, cultivable floras at $37^{\circ} \mathrm{C}$ and $22^{\circ} \mathrm{C}$ showed lower levels than in DUWLs where legionellae were not detected. N evertheless, this association was not statistically significant and, therefore, was not predictive of L. pneumophila detection 18 . Göksay and colleagues did not detect legionellae in DUWLs, but reported high Pseudomonas detection rate $(24 \%)$, the same values reported in the present survey, and of total viable flora at $27^{\circ} \mathrm{C}$ higher than the ADA threshold (97\%), suggesting that, as in the present study, Psudomonadaceae could prevent Legionelleaceae growth in waterlines ${ }^{19}$. Similar results, that is, high total viable flora and high Pseudomonas detection level associated with Legionella undetected in water reservoirs of dental units was reported by Szymańska and Sitkowska ${ }^{28}$ and by Veronesi and colleagues, who reported that $24 \%$ dental units were contaminated by Legionella spp., $54 \%$ by P. aeruginosa, while only $0.6 \%$ were contaminated by both microorganisms ${ }^{29}$. An inverse association between L. pneumophila and P. aeruginosa also was reported by Aprea and colleagues. These authors found legionellae and $\mathrm{P}$. aeruginosa in $76 \%$ and $33 \%$ water samples from DUWLs of a dental hospital highly contaminated by Legionella, respectively ${ }^{20}$.

\section{Conclusion}

The reported studies corroborate the results of the present survey that despite the more or less significant associations between microbiological parameters and legionellae in the output water of DUWLs, none of these parameters seems to be an effective predictor of Legionella detection and, most importantly, none of them could be used as risk marker for legionellosis, Legionella infection, or even Legionella transmission. This is an important result which raises doubts regarding the use of the level of aerobic heterotrophic bacteria as risk marker of water quality of DUWLs. Indeed, the number of surveys reporting high levels of these bacteria in DUWLs is uncountable. Yet, neither cultivable heterotrophic bacteria are effective predictors of legionellosis or P. aeruginosa infection, as there are no reported cases in the world literature, nor they per se pose any risk for infection, once again because there are no reported cases in the world literature.

These data suggest that the risk for opportunistic pathogen infection or infectious disease transmission mediated by water from DUWLs is evaluable only using specific tests, such as legionellae detection at high levels. 


\section{LITERATURA / REFERENCES}

1. Rusin PA, Rose JB, Haas CN, Gerba CP. Risk assessment of opportunistic bacterial pathogens in drinking water. Rev Environ Contam Toxicol 1997;152:57-83.

2. Leclerc H, Schwartzbrod L, Dei-Cas E. Microbial agents associated with waterborne diseases. Crit Rev M icrobiol 2002;28(4):371-409.

3. Walker JT, Bradshaw DJ, Fulford MR, Marsh PD. Microbiological evaluation of a range of disinfectant products to control mixed-species biofilm contamination in a laboratory model of a dental unit water system. Appl Environ Microbiol 2003;69(6):3327-32.

4. Petti S, Iannazzo S, Tarsitani G. Allogenic succession between Pseudomonas and Legionella in the water distribution system of a dental hospital. Ann Microbiol 2004;54(1):25-30.

5. O’Donnell MJ, Boyle MA, Russell RJ, Coleman DC. Management of dental unit waterline biofilms in the 21st century. Future Microbiol 2011;6(10):1209-26.

6. Pankhurst CL, Coulter WA. Do contaminated dental unit waterlines pose a risk of infection? J Dent 2007;35(9):712-20.

7. Rangel-Frausto MS, Rhomberg P, Hollis RJ et al. Persistence of Legionella pneumophila in a hospital water system: a 13-year survey. Infect Control Hosp Epidemiol 1999;20(12):793-7.

8. Castiglia P, Liguori G, Montagna MT et al. Italian multicenter study on infection hazards during dental practice: control of environmental microbial contamination in public dental surgeries. BMC Public Health 2008;8:187.

9. Pankhurst CL, Coulter WA, Philpott-Howard J et al. Prevalence of legionella waterline contamination and Legionella pneumophila antibodies in General Dental Practitioners in London and Rural Northern Ireland. Br Dent J 2003;195(10):591-4.

10. Walker JT, Bradshaw DJ, Finney $M$ et al. Microbiological evaluation of dental unit water systems in general dental practice in Europe. Eur J Oral Sci 2004;112(5):412-8.

11. Petti S, Polimeni A. The rationale of guidelines for infection control in dentistry: precautionary principle or acceptable risk? Infect Control Hosp Epidemiol 2010;31(12):1308-10.

12. Ricci ML, Fontana S, Pinci F et al. Pneumonia associated with a dental unit waterline. Lancet 2012;379(9816):684.

13. Schoen ME, Ashbolt NJ. An in-premise model for Legionella exposure during showering events. Water Res 2011;45(18):5826-36.

14. Atlas RM, Williams JF, Huntington MK. Legionella contamination of dental-unit waters. Appl Environ Microbiol 1995;61(4):1208-13.

15. D'Arca AS, Annicchiarico LS, Bellante G, Petti S, Tomassini E. Contamination of Dental Units and their surroundings by Legionella pneumophila serogroup 6 and by Legionella micdadei. J Prev Med Hyg 1992:33(12):59-63.
16. Petti S, Polimeni A. Risk of methicillin-resistant Staphylococcus aureus transmission in the dental healthcare setting: a narrative review. Infect Control Hosp Epidemiol 2011;32(11):1109-15.

17. Petti S, Moroni C, Messano GA, Polimeni A. Detection of oral streptococci in dental unit water lines after therapy with air turbine handpiece: biological fluid retraction more frequent than expected. Future Microbiol 2013;8(3):413-21.

18. Zanetti F, Stampi S, De Luca G et al. Water characteristics associated with the occurrence of Legionella pneumophila in dental units. Eur J Oral Sci 2000;108(1):22-8.

19. Göksay D, Cotuk A, Zeybek Z. Microbial contamination of dental unit waterlines in Istanbul, Turkey. Environ Monit Assess 2008;147(1-3):265-9.

20. Aprea L, Cannova L, Firenze A, Bivona MS, A modio $E$, Romano N. Can technical, functional and structural characteristics of dental units predict Legionella pneumophila and Pseudomonas aeruginosa contamination? J Oral Sci 2010;52(4):641-6.

21. Messano GA, Sofan AAA, Petti S. Quality of air and water in dental healthcare settings during professional toothcleaning. Acta Stomatol Naissi 2013; 29(67): 1230-35; doi: 10.5937/asn1367230M.

22. Messano GA, Masood M, Palermo P, Petti S. Prevalence of reactive tuberculin skin test in dental healthcare workers and students. Acta Stomatol Naissi 2013; 29(67): 1242-48; doi: 10.5937/asn1367242M.

23. Petti S, Sofan AAA, Messano GA. Streptococcus pneumoniae carriage rate in healthy preadolescent dental patients. Acta Stomatol Naissi 2013; 29(67): 1242-54; doi: 10.5937/asn1367249P.

24. Messano GA, De Bono V, Architrave R, Petti S. Environmental and gloves' contamination by staphylococci in dental healthcare settings. A cta Stomatol Naissi 2013; 29(67): 1255-49; doi: 10.5937/asn1367255M.

25. Messano GA. Bacterial and fungal contamination of dental hygienists' hands with and without finger rings. Acta Stomatol Naissi 2013; 29(67): 1260-64; doi: 10.5937/asn1367260M .

26. Petti S, Messano GA, Polimeni A, Dancer SJ. Effect of cleaning and disinfection on naturally contaminated clinical contact surfaces. Acta Stomatol Naissi 2013; 29(67): 1265-72; doi: 10.5937/asn1367265P.

27. Petti S, Messano GA, Scully C. Antibody level and immunity against Hepatitis B virus infection among general dental practitioners. Acta Stomatol Nai2013; 29(67): 1273-78; doi: 10.5937/asn1367273P.

28. Szymańska J Sitkowska J. Bacterial contamination of dental unit waterlines. Environ $M$ onit A ssess 2013;185(5):3603-11.

29. Veronesi L, Capobianco E, Affanni P, Pizzi S, Vitali P, Tanzi ML. Legionella contamination in the water system of hospital dental settings. Acta Biomed 2007;78(2):117-22. 